\title{
Correction to: barriers and facilitators for the management of vertigo: a qualitative study with primary care providers
}

Anna-Janina Stephan ${ }^{1 *}{ }^{*}$, Eva Kovacs ${ }^{1,2 \dagger}$, Amanda Phillips $^{1,2}$, Jörg Schelling ${ }^{3}$, Susanne Marlene Ulrich ${ }^{1}$ and Eva Grill ${ }^{1,2,4}$

\section{Correction}

After publication of the original article [1] it was brought to the authors' attention that a sentence was missing in the acknowledgement section. The full acknowledgement is included in this Correction article:

\begin{abstract}
Acknowledgements
We would like to thank the participating PCPs who dedicated their time to our interviews. In addition, we would like to thank the Department of General Practice and Health Services Research, University Hospital Heidelberg, Heidelberg, Germany, for the provision of the German version of the Questionnaire of Chronic Illness Care in Primary Care (QCPC) [2].
\end{abstract}

\section{Author details}

${ }^{1}$ Institute for Medical Information Processing, Biometry and Epidemiology, Ludwig-Maximilians-Universität München, Marchioninistraße 17, 81377 Munich, Germany. ${ }^{2}$ German Centre for Vertigo and Balance Disorders, University Hospital, Ludwig-Maximilians-Universität München, Munich, Germany. ${ }^{3}$ Institute for General Practice and Family Medicine, University Hospital, Ludwig-Maximilians-Universität München, Munich, Germany.

${ }^{4}$ Munich Centre of Health Sciences, Ludwig-Maximilians-Universität München, Munich, Germany.

Received: 4 June 2018 Accepted: 6 June 2018

Published online: 15 June 2018

\section{References}

1. Stephan A-J, Kovacs E, Phillips A, Schelling J, Ulrich SM, Grill E. Barriers and facilitators for the management of vertigo: a qualitative study with primary care providers. Implement Sci. 2018;13(1):25.

2. Steinhaeuser J, Miksch A, Ose D, Glassen K, Natanzon I, Szecsenyi J, Goetz K. Questionnaire of chronic illness care in primary care-psychometric properties and test-retest reliability. BMC Health Serv Res. 2011;11:295.

\footnotetext{
* Correspondence: anna_janina.stephan@med.uni-muenchen.de

${ }^{\dagger}$ Anna-Janina Stephan and Eva Kovacs contributed equally to this work.

${ }^{1}$ Institute for Medical Information Processing, Biometry and Epidemiology,

Ludwig-Maximilians-Universität München, Marchioninistraße 17, 81377

Munich, Germany

Full list of author information is available at the end of the article
}

(c) The Author(s). 2018 Open Access This article is distributed under the terms of the Creative Commons Attribution 4.0 International License (http://creativecommons.org/licenses/by/4.0/), which permits unrestricted use, distribution, and reproduction in any medium, provided you give appropriate credit to the original author(s) and the source, provide a link to the Creative Commons license, and indicate if changes were made. The Creative Commons Public Domain Dedication waiver (http://creativecommons.org/publicdomain/zero/1.0/) applies to the data made available in this article, unless otherwise stated. 